\title{
TORTOR MANGILIGI DALAM UPACARA SAYUR MATUA PADA MASYARAKAT SIMALUNGUN KAJIAN TERHADAP NILAI SOSIAL
}

\author{
IMMANENSIA TAMBUN \\ Prodi Pendidikan Tari
}

\begin{abstract}
This study discusses the Tortor Mangiligi In Ceremony Sayur Matua At Simalungun Society Study on the Social Value.

To discuss the above research purposes, used theories related to the research topic, such as Tortor understanding, understanding Sayur Matua, Social Values and Implementation Process.

When the study are used in discussing Tortor Mangiligi In Ceremony Sayur Matua At Simalungun Society Study on Social Values for 3 (three) months, namely in June to August 2016. The study site is Dalig Raya, Pematang Raya, Simalungun. The population in this study is the traditional leaders of society Simalungun, Tortor Mangiligi video documentation, as well as actors in the ceremony Tortor Mangiligi Sayur Matua.Analisis data in this study using descriptive qualitative data collection techniques with literature study, observation, interviews, and documentation.

The results showed that, Tortor Mangiligi implemented as a form of respect for his children for services, kindness and hard work to his parents, and as a family party of gratitude to our Creator for longevity given to the parents of the deceased. Through the stages of planning to carry out the funeral ceremony event Sayur Matua up the process of implementation, the envisaged role of the alliance system that is ToluSahundulan and Lima Simelungun Saodaran. They are incorporated in the kinship system is an integral and inseparable relationship brotherly rope while their parents died, and they intertwined relationship between good communication, mutual respect, love, and cooperation in the success of traditional events Sayur Matua death
\end{abstract}

Keywords: Tortor Mangiligi, Sayur Matua ceremony, Social Values 


\section{PENDAHULUAN}

\section{A. Latar Belakang}

Suku Simalungun merupakan bagian dari etnis Batak yang berada di wilayah Sumatra Utara yang mempunyai warisan kesenian dari generasi sebelumnya. Di antara warisan bentuk kesenian tersebut, termasuk di dalamnya adalah Tortor, dalam bahasa Indonesia disebut tari. Tortor sudah menjadi bagian dari konteks adat Simalungun. Adat yang merupakan hasil cipta akal budi manusia, disebut namanya adat karena sudah dilakukan secara berulang-ulang dan sudah merupakan kelaziman dilakukan dari dulu dimana bila adat itu sebagai budaya maka yang tidak melaksanakannya disebut naso maradat (tidak beradat) yang berakibat rugi secara moral dalam arti seseorang itu akan merasakan malu dan jadi bahan omongan orang lain bila tidak melakukan dan melaksanakan adat ${ }^{1}$. Adat memiliki pengertian aturan-aturan perilaku serta kebiasaan yang telah berlaku di dalam pergaulan masyarakat ${ }^{2}$. Simalungun. Salah satu tortor yang menggambarkan hal tersebut adalah Tortor Mangiligi. Tortor Mangiligi ini lazim ditarikan pada saat upacara adat kematian Sayur matua

\footnotetext{
${ }^{1}$ Wawancara dengan Bapak Rimson Tambun

S.Th, S.H , Marindal Medan, 10 Juni 2016 ${ }^{2}$ Lihat di https://uulgintingg.wordpress.com/2012/03/02/hu kum-adat-yang-masih-berlaku-di-daerah-asalsumatera-utara/ . Diakses pada 10 juni 2016
}

(meninggal saat lanjut usia), dimana Tortor Mangiligi pada suku Simalungun hadir dalam upacara adat kematian Sayur Matua, yang dihadiri oleh keluarga dekat (suhut, sanina, dan tondong), dan didalam menarikan Tortor Mangiligi akan terjadi urutan-urutan atau rangkaian sosial dan religius yang mengenai kehidupan sosial dan hubungan kepada Sang Pencipta ${ }^{3}$.

Tortor Mangiligi adalah salah satu Tortor peninggalan masa lampau yang sedapat mungkin harus dilestarikan, dimana melalui Tortor Mangiligi tersebut terdapat adanya nilai sosial yang akan membantu terjaganya hubungan sosial yakni silahturahmi atau hubungan baik dengan sanak saudara. Dan memberikan pemahaman bagi pihak lain yang berpartisipasi dalam acara kematian Sayur Matua Pada masyaraka Simalungun, bahwa pentingnya nilai sosial yang tergambar melalui adanya sistem kekerabatan dalam suatu acara adat.

\section{b. Identifikasi Masalah}

Dalam latar belakang penelitian ini, maka penulis perlu membuat identifikasi masalah yang bertujuan untuk memperoleh gambaran yang luas terhadap apa yang akan diteliti serta agar penelitian yang dilakukan menjadi terarah serta cakupan masalah yang diketahui tidak terlalu luas.

\footnotetext{
${ }^{3}$ Wawancara dengan narasumber, Bapak Sahat Damanik , pada tanggal 14 Juni 2016
} 
Identifikasi masalah tersebut sesuai dengan pendapat Sugiyono (2008:385) yang mengatakan bahwa : "Untuk dapat mengidentifikasi masalah dengan baik, maka peneliti perlu melakukan penelitian studi studi pendahuluan ke objek yang akan diteliti, melakukan observasi dan wawancara keberbagai sumber sehingga semua permasalahan dapat teridentifikasi",4.

\section{c. Pembatasan Masalah}

Mengingat luasnya cakupan masalah yang diidentifikasi serta keterbatas waktu, dana dan kemampuan teoritis maka peneliti perlu mengadakan pembatasan masalah untuk memudahkan masalah yang dihadapi dalam penelitian. Hal ini dilakukan agar dalam proses penelitian, pembahasan tidak meluas sehingga penelitian yang dilakukan lebih terarah.

Oleh sebab itu pembatasan masalah yang dilakukan terhadap penelitian ini adalah:

"Bagaimana nilai sosial yang terkandung didalam proses pelaksanaan Tortor Mangiligi dalam upacara Sayur Matua pada masyarakat Simlungun ?"

\section{D.Perumusan Masalah}

"Tortor Mangiligi Dalam Upacara Sayur Matua Pada Masyarakat Simalungun Kajian Terhadap Nilai Sosial”.

\section{E. Tujuan Penelitian}

"Mendeskripsikan bagaimana nilai sosial yang terkandung didalam proses pelaksanaan Tortor Mangiligi dalam upacara Sayur Matua pada masyarakat Simalungun".

\section{F.Manfaat Penelitian}

1. Sebagai bahan masukan bagi penulis dalam menambah pengetahuan dan wawasan mengenai Tortor Mangiligi.

2. Sebagai bahan apresiasi bagi masyarakat di luar etnis Simalungun dalam memahami adat istiadat masyarakat Simalungun.

3. Sebagai informasi tertulis tentang adanya nilai sosial dalam proses pelaksanaan Tortor Mangiligi dalam upacara SayurMatua pada masyarakat Simalungun.

4. Sebagai masukan bagi generasi muda Simalungun untuk terus memelihara adat istiadatnya

\section{LANDASAN TEORITIS DAN KERANGKA KONSEPTUAL \\ 1. Tortor Mangiligi}

Menurut Sumbayak Japiten (2001) dalam bukunya, Mangiligi ialah menari bersama antara hasuhuton dengan

\footnotetext{
${ }^{4}$ https://sefmimijuliati.wordpress.com/2011/10/26 /identifikasi-masalah-batasan-masalah-sertarumusan-masalah/
} 
tutur/rombongan dalam rangka melayat jenazah $^{5}$. Tortor dapat membedakan kelompok status yang menari, misalnya dalam Tortor Mangiligi pada masyarakat Simalungin, dimana Tortor Mangiligi adalah Tortor yang ditarikan atau ditampilkan pada suatu acara adat kematian sayur matua yang dilakukan di siang hari untuk menyambut para pelayat atau sanak saudara dimana dalam pelaksanaanya diikat oleh sistem kekerabatan Simalungun yakni, Tolu Sahundulan.

\section{Pengertian Sayur Matua}

Sayur matua adalah orang yang meninggal dunia di saat dia telah memiliki anak yang semuanya sudah mandiri dan berkeluarga juga sudah memiliki cucu. Pada situasi seperti ini biasanya kematiannya menjadi kebanggan bagi keluarga yang ditinggalkan. Orang yang meninggal dalam keadaan sayur matua dianggap telah sempurna menurut adat Simalungun.

\section{Pengertian Masyarakat}

Mayarakat dalam penelitian ini diuraikan berdasarkan pendapat beberapa ahli sosiologi. Pengertian ini disajikan untuk melengkapi penjelasan Tortor Mangiligi pada masyarakat Simalungun agar dapat dihubungkan menjadi satu

\footnotetext{
${ }^{5}$ Sumbayak Japiten, 2001. Refleksi Habonaran Do Bona Dalam Adat Budaya Simalungun, Pematang Raya : Dinas Pendidikan Dan Pengajaran.
}

kesatuan yang tidak terpisahkan. Berikut adalah pengertian masyarakat menurut pendapat tiga ahli yang sudah dirangkum oleh Soekamto (1969:28), yaitu :

(Mac Iver dan Page)"Masyarakat ialah suatu sistim dari kebiasaan dan tata cara, dari wewenang dan kerjasama antara berbagai kelompok dan penggolongan, dari pengawasan tingkah laku serta kebebasankebebasan manusia. Keseluruhan yang selalu berubah ini kita namakan masyarakat. Masyarakat merupakan jalinan hubungan sosial, dan msyarakat selalu berubah".(Ralph Linton) "Masyarakat merupakan setiap kelompok manusia yang telah hidup dan bekerja bersama cukup lama sehingga mereka dapat mengatur diri mereka dan menganggap diri mereka sebagai suatu kesatuan sosial dengan batasbatas yang dirumuskan dengan jelas)".(Selo Soemardjan)."Masyarakat adalah orang-orang yang hidup bersama, yang menghasilkan kebudayaan", 6 .

\section{Nilai Sosial}

Berpijak pada pendapat Robin Wiliam, maka dari itu, nilai sosial yang dijunjung tinggi dalam arti dihormati tadi akan menjadi pegangan hidup oleh masyarakat dalam menentukan sikap di kehidupan sehari-hari, juga dalam berinteraksi dengan

\footnotetext{
${ }^{6}$ Lihat di http://hedisasrawan.blogspot.co.id/2013/04/objek -sosiologi-artikel-lengkap.html
} 
manusia lainnya yang dapat memberikan kesejahteraan dengan terjaganya hubungan baik antar sesama kerabat. Dimana hal tersebut tergambar dalam Tortor Mangiligi yakni adanya nilai sosial dijunjung tinggi dalam tahapan-tahapan sampai kepada proses pelaksanaan Tortor Mangiligi ini, hal tersebut terlihat melalui sistem kekerabatan masyarakat Simalungun yang wajib hadir dalam segenap aktivtas adat isitiadat mereka.

\section{Pengertian Proses Pelaksanaan}

Proses dalam Kamus Modern Bahasa Inonesia berarti urut-urutan jalannya peristiwa. Jika dihubungkan dengan pelaksanaan dalam Tortor Mangiligi maka yang dimaksud dengan proses pelaksanaan adalah urut-urutan jalannya peristiwa manortor dalam upacara Sayur Matua, dikaitkan dengan orang-orang yang menarikannya, yang berdasarkan pada hukum adat Tolu Sahundulan dalam masyarakat Simalungun,

\section{B. Kerangka Konseptual}

Kerangka konseptual adalah rancangan/ gambaran yang disusun menjadi kerangka ilmiah yang telah dianalisa oleh penulis melalui sumber peneliti lapangan dan teori yang didapat dari beberapa buku, sehingga penelitian semakin terarah.

\section{METODOLOGI PENELITIAN}

\section{A. Metodologi Penelitian}

Metodologi penelitian adalah suatu tujuan dalam penelitian. Bila tidak memiliki metode maka peneliti tidak akan memiliki cara atau teknik dalam memecahkan masalah, Dalam pelaksanaan penelitian ini, peneliti menggunakan metode deskriptif yang bersifat kualitatif karena memberikan keterangan yang akurat dan jelas sesuai yang dibutuhkan.

\section{B. Lokasi dan Waktu Penelitian}

Adapun yang menjadi lokasi penelitian ini adalah di Dalig Raya, Pematang Raya, Kabupaten Simalungun. Pemilihan lokasi ini dikarenakan narasumber yang mengetahui tentang tarian yang sedang penulis teliti bertempat di Pematang Raya, Kabupaten Simalungun tersebut.

\section{Waktu Penelitian}

Waktu yang digunakan untuk megadakan penelitian dalam rangka mengupas kajian dan mendapatkan informasi serta data-data yang akurat berkaitan dengan penelitian ini yaitu mulai dari bulan Juni 2016 sampai Agustus 2016.

\section{Populasi dan Sampel Populasi}

"Populasi adalah wilayah generalisasi yang terdiri atas obyek/subyek yang mempunyai kualitas dan karakteristik tertentu yang diterapkan oleh penelitian untuk dipelajari dan ditarik 
kesimpulannya".Maka dapat diambil kesimpulan bahwa populasi dalam penelitian ini adalah tokoh adat masyarakat Simalungun, video dokumentasi Tortor Mangiligi, serta pelaku Tortor Mangiligi dalam upacara Sayur Matua yang terbagi dalam kelompok suhut, sanina, dan boru. .

\section{Sampel}

Dalam menentukan sampel dalam penelitian ini, peneliti berpedoman pada pendapat Arikunto (1996:17) yang menyatakan bahwa sampel adalah bagian atau wakil populasi yang diteliti. Jika subjeknya lebih dari 100, maka diambil $25 \%$ dari jumlah populasi sebagai sampel penelitian.Berdasarkan pendapat di atas, maka sampel dalam penelitian ini merupakan tokoh adat Simalungun di Daling Raya, dan video dokumentasi Tortor Mangiligi dalam upacara Sayur Matua.

\section{Teknik Pengumpulan Data}

1. Pengamatan

2. Wawancara

3. Dokumentasi

4. Studi Kepustakaan

\section{Teknik Analisis Data}

Teknik analisis data dilakukan bertujuan untuk mengolah data-data yang diperoleh ketika proses penelitian agar penelitian dapat dipertanggung jawabkan sesuai dengan kebenaran yang ada. Metode pengolahan data deskriptif kualitatif yaitu penyajian data yang terkumpul melalui teknik pengumpulan data lalu diarahkan melalui analisis deskriptif kualitatif untuk menjelaskan topik dari suatu penelitian yang akan diteliti tersebut

\section{HASIL PENELITIA DAN PEMBAHASAN}

\section{A. Gambaran Umum Lokasi Penelitian}

\section{Letak Geografis}

Kecamatan Raya merupakan kecamatan terbesar dan terluas di Kabupaten Simalungun. Kecamatan ini merupakan Ibukota Kabupaten Simalungun. Kecamatan ini memiliki luas berkisar 328,50 Km2. Kecamatan Raya mencakup 17 nagori/desa yaitu: Nagori Dolog Huluan, Raya Usang, Raya Bayu, Dalig Raya, Merek Raya, Bahapal Raya, Sondi Raya, Bah Bolon, Raya Huluan, Siporkas, Silou Huluan, Silou Buttu, Bonguron Kariahan, Sihubu Raya, Raya Bosi, Simbou Baru, Bintang Mariah dan 1 
kelurahan, yaitu Kelurahan Pematang Raya.

Pada penelitian ini, daerah kecamatan Raya tepatnya di Dalig Raya adalah salah satu daerah dari Kecamatan Raya yang menjadi lokasi dilaksanakannya penelitian.

\section{Keadaan Penduduk}

Penduduk asli kabupaten Simalungun adalah suku simalungun. Jumlah penduduknya adalah 841.189 jiwa. Meskipun Kabupaten Simalungun adalah tanah leluhur orang Simalungun, namun belakangan ini secara statistik orang Simalungun adalah penduduk peringkat mayoritas ke-tiga di kabupaten Simalungun, setelah orang jawa dan orang yang berasal dari Toba. Orang Simalungun justru diperkirakan lebih banyak tingggal di luar wilayah Simalungun.Asal Usul Simalungun.

Suku Simalungun adalah salah satu suku asli yang ada dari provinsi Sumatera Utara. Dahulu di wilayah Sumatera Utara terdapat sebuah kampung yang bernama kampung Nagur, di kampung Nagur terdapat sebuah kerajaaan. Masyarakat Simalungun, Kabupaten Simalungun adalah salah satu Kabupaten yang berada di Provinsi Sumatera Utara, yang didiami oleh beberapa suku diantaranya suku Batak Toba, Karo, Mandailing. Sistem Kekerabatan Masyarakat Simalungun

3. Sistem Religi

B. Upacara Adat Pada Masyarakat Simalungun

\section{Malas ni uhur (Kabar gembira)}

Malas ni uhur adalah suatu acara adat yang didalamnya terdapat sukacita dan kegembiraan dan kesenangan. Upacara adat ini berupa upacara pesta tuan (robu-robu horja tuan) atau pesta untuk memulai bertani untuk hasil yang memuaskan, upacara marhajabuan (pernikahan), upacara pemberian nama, upacara memasuki rumah baru dan masih banyak lainnya.

\section{Pos ni uhur}

Pos ni uhur adalah upacara kematian bagi masyarakat Simalungun. Dalam pelaksanaan upcara kematian pada setiap anggota keluarga atau kerabat yang meninggal sangat dihormati oleh masyarakat Simalungun, karena pada saat acara- 
acara seperti inilah peran dari sistem kekerabatan dijalankan.

Dalam hal ini peneliti berfokus pada kematian Sayur Matua, dimana hal diatas tersebut tergambar pada jenis kematian Sayur Matua pada Masyarakat Simalungun, dimana Sayur Matua adalah kematian dari seseorang yang mana seluruh anaknya sudah berkeluarga dan ia sudah memiliki cucu baik dari anaknya lakilaki maupun perempuan.

\section{Sistem Kekerabatan Simalungun}

Simalungun mempunyai Tolu Sahundulan dan Lima Saodoran (Tiga sekedudukan, Lima sebarisan, yang merupakan sistem kekerabatan orang Simalungun, dimana sistem kekerabatan Tolu Sahundulan itu meliputi Tondong yaitu pihak mertua (pemberi anak gadis), Boru yaitu pihak penerima anak gadis, dan Sanina yaitu saudara semarga, saudara kandung, saudara dari lain nenek, pariban, dan teman sepergaulan). Sistem kekerabatan inilah yang berperan dalam proses pelaksanaan acara adat kematian Sayur matua yang didalamnya merkalah yang menjadi bagian dari Tortor Mangiligi.

\section{Nilai Sosial Tortor Mangiligi} Pada Upacara Adat Kematian Sayur Matua

\section{a. Perencanaan pelaksanaan}

\section{Tortor Mangiligi}

Beberapa hal yang harus dilakukan sebagai hal pertama sebelum hari pelaksanaan acara Tortor Mangiligi dalam upacara kematian Sayur Matua dilaksanakan adalah berperannya orang-orang yang tergabung didalam sistem kekerabatan Tolu Sahundulan, Lima Sodoran, dimana dalam aktivitas-aktivitas orang-orang yang tergabung dalam sistem kekerabatan tersebut terdapat adanya nilai sosial yakni mereka berkumpul untuk bermusyawarah untuk mufakat dimana membicarakan, menentukan , merumuskan secara adat hal-hal yang penting menyangkut keperluan dalam pelaksanaan Tortor Mangiligi dalam 
upacara kematian Sayur Matua, dan mereka yang tergabung dalam Tolu Sahundulan, Lima Saodoran membantu suhut (yang punya acara/urusan adat) baik bantuan dalam bentuk materi maupun tenaga demi terlaksananya acara adat dengan baik.

\section{b. Proses pelaksanaan Tortor}

\section{Mangiligi}

Pada proses pelaksanaan Tortor Mangiligi ini terdapat didalamnya adanya nilai sosial, dimana pelaksana Tortor Mangiligi itu dibagi kedalam 2 pihak yang manortor yakni : Pihak pertama yang terdiri dari Suhut (pihak yang punya acara atau yang berduka). Pihak kedua yang terdiri dari Tondong (keluarga pihak yang memberikan anak wanitanya kepada marga lain menjadi isterinya dan semua saudara-saudara yang terkait dengan keluarga yang memberi anak wanita itu menjadi tondong dari semua keluarga yang terkait pula dengan sipenerima wanita itu, dimana pemberi wanita menjadi isteri kepada marga / keluarga lain ada di lakukan turun temurun yang masih terbina dan lestari sampai sekarang disebut nama - nama bagiannya ialah sebagai berikut : Tondong pamupus (keluarga/ibu bapak dari ibu yang melahirkan kita dari saudara laki - laki dari ibu kita ( ipar dari bapak kita), tondong bona (keluarga yang melahirkan nenek kita dan saudara saudaranya), tondong bona ni ari (keluarga yang melahirkan nenek bapak kita semua tondong seterusnya ketingkat neneknya nenek bertemu pada Tondong asal yang juga disebut Tondong Tua atau Tondong bona ni ari), tondong mangihut (pemberi isteri bagi saudara laki-laki) atau tondong jabu dan tondong ni tondong (yang melahirkan ibu/isteri atau mertua ibu/isteri), sanina (saudara satu ayah/ibu), pariban (sebutan bagi orang yang dapat kita jadikan pasangan(suami/istri) atau adik/kakaknya), boru jabu atau appuan (pimpinan dari semua boru, anak boru 
jabu dituakan karena bertanggungjawab pada tiap acara suka/duka cita), boru mintori (suami/istri dari kemanakan atau anak laki/perempuan dari saudara perempuan kandung), dongan sahuta (teman sekampung atau kolega lainnya).

Melalui tahapan - tahapan perencanaan untuk melaksanakan acara upacara kematian Sayur Matua sampai kepada proses pelaksanaan Tortor Mangiligi yang dijelaskan diatas, menunjukan terdapatnya nilai sosial didalamnya, yang mana melalui peran sistem kekerabatan orang Simalungun yakni Tolu Sahundulan dan Lima Saodaran. dimana mereka yang tergabung dalam sistem kekerabatan tersebut adalah satu kesatuan yang tidak dapat terpisahkan hubungan tali persaudaraannya walau orang tua mereka meninggal, dan diantara mereka terjalin hubungan saling menghormati, mengasihi, serta bekerjasama dalam menyukseskan acara adat kematian Sayur Matua.

\section{PENUTUP}

\section{A. Kesimpulan}

1. Upacara kematian Sayur matua dibagi menjadi dua jenis acara, yakni acara Mandiguri (dilaksanakan di dalam rumah pada malam hari yang bertujuan berjaga di dekat orang tua yang meninggal sampai pagi menjelang), dan acara Mangiligi yang menjadi fokus penelitian penulis (dilaksanakan di luar rumah pada siang hari yang dimana untuk menyambut para pelayat yakni sanak saudara dan kerabat lainnya dan dilengkapi dengan adanya Gonrang dan Tortor Mangiligi.

2. Tortor Mangiligi dalam upacara adat kematian Sayur Matua wajib dilaksanakan dan ditarikan karena itu merupakan bagian dari konteks adat Simalungun, dimana Tortor Mangiligi itu merupakan hasil cipta akal budi yang sudah dilakukan secara berulang-ulang dan sudah merupakan kelaziman dilakukan 
dari dulu sampai sekarang, maka yang tidak melaksanakan Tortor Mangiligi dalam upacara adat kematian Sayur Matua disebut naso maradat (tidak beradat) yang berakibat rugi moral dalam arti pastinya seseorang itu akan merasakan malu dan jadi bahan omongan orang lain bila tidak melakukan dan melaksanakan adat.

3. Bagi masyarakat Simalungun, pelaksanaan upacara kematian pada setiap anggota kerabat yang meninggal sangat dihormati apalagi setelah berada pada kematian Sayur Matua, karena sebagai wujud penghormatan anak-anaknya atas jasa-jasa, kebaikan, serta kerja keras orang tua yang meninggal Sayur Matua dan ungkapan syukur pihak keluarga kepada Sang Pencipta atas umur panjang yang diberikan kepada orang tua yang meninggal tersebut.

4. Melalui tahapan-tahapan perencanaan untuk melaksanakan acara upacara kematian Sayur Matua sampai kepada proses pelaksanaan, serta gerakan-gerakan pada Tortor Mangiligi tersebut tergambar nilai sosial melalui peran sistem kekerabatan orang Simalungun yakni Tolu Sahundulan dan Lima Saodaran. dimana mereka yang tergabung dalam sistem kekerabatan tersebut adalah satu kesatuan yang tidak dapat terpisahkan hubungan tali persaudaraannya walau orang tua mereka meninggal, dan diantara mereka terjalin hubungan saling menghormati, mengasihi, serta bekerjasama dalam menyukseskan acara adat kematian Sayur Matua.

\section{B. Saran}

- kepada masyarakat Simalungun khususnya bagi generasi muda untuk semakin lebih mengenal dan menjaga hubungan sistem kekerabatan yang ada dan adatistiadat didaerahnya, agar 
terjalinnya hubungan baik terhadap sesama.

- Kepada pihak pelaku-pelaku seni agar mendokumentasikan upacaraupacara adat dan kebudayaan dalam hal kesenian, terutama seni tari, agar nantinya dapat diperkenalkan dan sebagai salah satu daya tarik kepada turis-turis yang mengunjungi Simalungun dan wilayah-wilayah lainnya khususnya di Sumatera Utara.

- Kepada Pemerintah Daerah dalam hal ini Dinas Pendidikan di kebudayaan Kabupaten Simalungun, agar tetap melakukan pembelajaran Seni Budaya Simalungun kepada peserta didik mulai dari tingkat Sekolah Dasar sampai tingkat Sekolah Menengah (Sebagai mata pelajaran muatan lokal atau kearifan lokal yang memuat pelajaran khusus sesuai dengan kebutuhan daerah), dan kalau memungkinkan sampai tingkat Perguruan Tinggi, demi lestarinya nilai budaya yang sangat baik dan sangat berguna ini.

- Kepada para tokoh adat dan pakarpakar budaya Simalungun, agar menulis buku-buku refrensi yang banyak dalam rangka kebutuhan refrensi, acuan dan bacaan generasi muda Simalungun dan pemerhati tentang budaya lainnya. 


\section{DAFTAR PUSTAKA}

Agustono Budi,dkk. (2012). Sejarah Etnis Simalungun. Siantar: Percetakan Hutaria Jaya.

Asli Dearnita Saragih. (2008) Tortor Mangiligi Dalam Upacara Sayur Matua Pada Masyarakat Simalungun. Skripsi, FBS Universitas Negeri Medan.

Efendi Zainal Hasibuan, 2015. Panduan Praktis Menulis Skripsi, Tesis, dan Disertasi (Kulitatif, Kuantitatif, dan Kepustakaan. Medan : Penerbit Mitra.

M.Setiadi Elli, M.Si, dkk. (2012). Ilmu Sosial Budaya \& Dasar. Edisi Kedua, Jakarta : Kencana Prenada Media Grup.

Nugrahaningsih RHD, \& Heniwaty Yusnizar ,. (2012). Tari Identitas dan Resistensi, Medan: Unimed Pers.

Nurwani, 2012. Pengetahuan Seni Tari, Unimed pers. Medan : Hal.19

Rinda Turnip. (2016) Makna Gerak Tortor Mangondas dalam Upacara Kematian Saur Matua Pada Masyarakat Batak Toba. Skripsi, FBS Universitas Negeri Medan.

Sipayung Juniadi, 2013. Mengenal Tortor \& Hangoluan Simalungun, Pematang Siantar : Hutarih Jaya.

Sinaga Richard, 2012. Meninggal Adat Dalihan Natolu. Jakarta : Dian Utama dan Kerabat.

Sumbayak Japiten .(2001). Refleksi Habonaran Do Bona Dalam Adat Budaya Simalungun, Pematang Raya : Dinas Pendidikan dan Pengajaran.
Syarfina Tengku, 2016. Kamus Pelajar Simalungun-Indonesia. Medan : Penerbit Mitra Medan.

Tambun Rimson, Hukum Adat Dalihan Na Tolu, 2012. Medan : Penerbit Mitra.

Teti Elena Siburian. (2013), Analisis Pertunjukan Toping-toping Pada Pesta Rondang Bittang Ke XIVII Di Saribu Dolok Kecamatan Silima Kuta Kabupaten Simalungun. Skripsi, Medan: FIB Universitas Sumatera Utara.

Wawancara dengan Bapak Rimson Tambun S.Th, S.H , Marindal Medan, 10 Juni 2016

Wawancara dengan narasumber, Bapak Sahat Damanik , pada tanggal 14 Juni 2016

\section{DAFTAR ACUAN INTERNET}

http://www.satujam.com/pengertianbudaya/

http://eprints.uny.ac.id/9205/2/bab\%20108209241046.pdf

http://id.wikipedia.org/wiki/Nilai_sosial.Di aksespada 9 Juni 2016

http://charliemuhammad.blogspot.co.id/2012/0 4/pemikiran-emile-durkheim.html

http://alfinnitihardjo.ohlog.com/nilaisosial.oh1 12673.html.Diaksespada 9 Juni 2016

http://ragam-budayabatak.blogspot.co.id/ diakses tanggal 10 juni 2016

https://uulgintingg.wordpress.com/2012/03 /02/hukum-adat-yang-masihberlaku-di-daerah-asal-sumaterautara/

https://sefmimijuliati.wordpress.com/2011/ 10/26/identifikasi-masalah- 
batasan-masalah-serta-rumusanmasalah/

http://hedisasrawan.blogspot.co.id/2013/04 /objek-sosiologi-artikellengkap.html

http://blogdeee.blogspot.co.id/2011/03/mac am-macam-nilai-menurutprof.html

https://buntokhacker.wordpress.com/materi -pemelajaran/sosial/pengertiandan-definisi-sosial-menurut-paraahli/

http://www.radhitisme.com/2011/03/penga ntar-sosiologi-ii.html

http://kumpulanskripdanmakalah.blogspot. co.id/2015/10/v behaviorurldefaultvmlo.html

http://www.gurupendidikan.com/14pengertian-observasi-menurutpara-ahli-terbaru/ 